\title{
Exporting versus foreign direct investment: Learning through propinquity*
}

\author{
Anthony Creane ${ }^{\dagger} \quad$ Kaz Miyagiwa ${ }^{\ddagger}$
}

May 6, 2015

\begin{abstract}
This paper considers the strategic role learning plays on foreign direct investments (FDI) under demand and cost uncertainty. FDI allows a foreign firm to respond more effectively to changing local demand than if it exports. With cost uncertainty, however, FDI has a second effect. Since a foreign firm procures inputs locally as does its home country rival, the problem of learning is transformed from about its private parameter to about the common parameter, which proves harmful in both price and quantity competition. We show that FDI decisions depend on whether the firm faces relatively more demand or cost uncertainty, how differentiated the rival's product is, and to what extent inputs are locally procured.
\end{abstract}

Keywords: FDI, uncertainty, strategic competition, access mode choice, welfare, oligopoly. JEL classification: D83, F12, F21

*This paper is based in part on an earlier working paper Creane and Miyagiwa (2007). We thank Jim Anderson, Carl Davidson, Steve Matusz, Denis Medvedev and participants at the European Trade Study Group, Hitotsubashi Trade Conference, IIO Conference, Latin American Econometric Society meetings, Midwest International Economics meetings, and at seminars at George Washington, Kobe, Michigan State and Ritusmeikan Universities for their comments we received at various stages of development.

${ }^{\dagger}$ Department of Economics, University of Kentucky, Lexington, KY 40506; USA a.creane@uky.edu.

${ }_{\ddagger}^{\ddagger}$ Department of Economics, Florida International University, 11200 SW 8th Street, Miami, FL 33199.USA; Hitotsubashi Institute for Advanced Study; and ISER, Osaka Universisty kmiyagiwa@gmail.com. 


\section{Introduction}

It is well-known that since the 1980's, foreign direct investment (FDI) has grown much faster than GDP or trade. The impressive rise in multinational activity has prompted international trade economists to seek reasons why some firms choose FDI over exporting. The seminal works of Caves (1971), Helpman (1984), and Markusen (1984) have established that FDI decisions are influenced by technology characteristics such as firm-level and plant-level scale economies as well as country characteristics such as market sizes, differences in marginal costs, and trade costs. ${ }^{1}$ Recent extensions in this strand of literature emphasize what is known as the proximity-concentration trade-off, i.e., FDI is chosen over exporting if the FDI setup cost is cheaper than the transport costs.

A different approach has focused on the informational barriers created by international borders. Some work has considered private information issues for the firm considering FDI ${ }^{2}$ while other has focused on how FDI can be affected by cost or demand uncertainty. In the latter strand of literature, for example, Sung and Lapan (2000) show that exchange-rate volatility can motivate a firm to maintain plants in multiple countries so as to produce in the least-cost country. Similarly, Aizenman and Marion (2004) examine how productivity shocks affect the choice between vertical and horizontal FDI. With respect to demand uncertainty, Rob and Vettas (2003) examine how demand learning affects a monopoly firm's timing to switch from exporting to FDI. ${ }^{3}$ In related work, Qiu and Zhou (2006) consider how international merger can gain a firm demand information about its export market, thereby providing one resolution to the "merger paradox" (that mergers are unprofitable in Cournot competition).

\footnotetext{
${ }^{1}$ Caves (1971) and Markusen (1995, 2002) review the literature.

${ }^{2}$ This approach is pioneered by Ethier (1986), who places internalization at the center of FDI decisions; see also Horstmann and Markusen (1996). More recently, Bagwell and Staiger (2003) examine how FDI can signal a firm's cost to rival firms producing in the consuming country and Katayama and Miyagiwa (2009) examine how FDI can signal a foreign monopoly's product quality.

${ }^{3}$ Demand for a firm's product can change suddenly due to changes in consumer preferences or other economic conditions, especially if a firm sells intermediate goods to downstream firms. In such a case, a firm can respond more quickly by locating in the consuming country, than by producing and shipping the product from its overseas plant.
} 
These papers examine greenfield FDI decisions (i.e., whether to build a new plant) in non-strategic environments. ${ }^{4}$ However, as Neary (2010) notes, trade is dominated by large firms - oligopolists - and so strategic environments should also be examined as "whether or not a country hosts any superstar firms is likely to matter for many questions." In this paper, we focus thus on the role of learning on the FDI decision in strategic environments, where the foreign firm chooses between FDI and exporting to compete with the home country firm in the home country. This focus on learning in strategic environments allows new insights into the way FDI decisions are affected by such factors as the type of competition, the degree of product substitutability and the extent in which FDI requires "local content."

Another contribution we make to the literature is that, while the other papers considered either cost or demand uncertainty in isolation, we examine both types of uncertainty, the interplay of which turns out to be critical to the analysis. With demand uncertainty we use the standard framework (e.g., Qiu and Zhou 1996) to formalize the idea that a firm can learn more about demand shocks by locating production in the consuming country. That is, the local firm knows more about its country's demand shocks, while the foreign firm gains that knowledge only by choosing FDI and producing in the home country. As for cost uncertainty, we assume that production uses both locally procured and internationally traded inputs. Local input and international input prices all fluctuate independently of one another. Thus, when the foreign firm exports, the foreign and home (domestic) firms produce in separate countries and face different local cost shocks (learning about a private parameter). In contrast, when it chooses FDI, the foreign firm procures local inputs in the home country (as assumed in the scale-proximity trade-off literature). This has two implications. First, the foreign firm faces the same local cost shocks that the home firm does. As a result, the foreign firm learns about the rival's cost, which ceteris paribus is valuable to the foreign firm in strategic environments. For example, as firms employ labor from the common labor market or labor union, seeing wages increase reveals to the foreign firm that the home firm is also facing higher labor cost. Other aspects of FDI, e.g., using common local suppliers, enhance

\footnotetext{
${ }^{4}$ Greenfield FDI is not an option in Qiu and Zhou's (2006) analysis as the foreign firm can only acquire an already operating home firm.
} 
this effect. However, this also means that the cost learning problem is now one regarding a common parameter. That is, by choosing FDI over exporting, a firm changes the nature of cost learning from being about a private parameter to being about a common parameter. As a shorthand, we will sometimes refer to this hitherto unexamined informational effect as "learning correlation," which we show is harmful to firms when they compete strategically.

Formally, our model has three stages. In the first stage, the foreign firm chooses its access mode between FDI and exporting. In the second stage, Nature resolves demand and cost uncertainty and reveals some or all of the realization to firms, depending on the access mode chosen in the first stage. In the third stage, based on this information firms compete in the home market in quantities (price competition is considered later). The model yields the following results. First, if there is no learning, then FDI is determine by the traditional proximity-concentration trade-off: uncertainty has no effect. If, instead, there is learning, then when demand uncertainty is sufficiently larger than cost uncertainty or FDI uses a sufficiently small portion of "local content," the foreign firm prefers FDI to exporting ceteris paribus. Second, FDI decisions are also influenced by the degree of product differentiability. Specifically, FDI becomes more attractive as the firms produce more differentiated goods. This is because as the goods become more differentiated, demand information becomes more valuable and at the same time the learning correlation effect is mitigated.

We can summarize our main results as follows. A foreign firm chooses FDI over exporting (i) when cost uncertainty is small relative to demand uncertainty, (ii) "local content" is not too large a fraction of the firm's production costs, and (iii) when rivals produce sufficiently differentiated goods. Interestingly, these principal results hold both in quantity and price competition, unlike many results in oligopoly models that depend crucially on the type of competition. ${ }^{5}$ Finally, these results suggest not only a reason why FDI occurs, but a reason why it has been growing. To the extent that upstream multinationals choose FDI and produce intermediate goods locally, input markets become globalized across countries. As costs become less dependent on local shocks, FDI becomes more attractive to downstream

\footnotetext{
${ }^{5}$ One exception to this can be found in Etro (2011) who revisits optimal export policy and shows that it is always optimal to subsidize exports when, contrary to previous work, entry is endogenous.
} 
multinationals relative to exporting. Thus, FDI by multinationals producing input goods may be a catalyst for FDI by multinationals using those inputs.

In addition to presenting our principal results as regards FDI decisions, we also compare the welfare effects between FDI and exporting for the consuming (home) country. First, we find that the home firm is usually harmed by FDI when the foreign firm finds FDI profitable. ${ }^{6}$ The primary reason is that a correlation of learning works symmetrically on both firms, harming the local firm as much as it does the foreign firm, but the local firm does not get the benefit of gaining demand information. As for home consumers, we find that the effect of FDI on consumer surplus - unlike our previous results - depends on whether the firms compete in prices or quantities. With quantity competition, consumers benefit from FDI because the foreign firm responds to high demand by expanding output. While the opposite holds when demand is low, consumers' marginal value is also lower in that case, so the loss from reduced consumer surplus when demand is low is dominated by the gain in consumer surplus from an output expansion at high demand. However, in price competition this effect is reversed because a firm raises its price when demand is high. As a result, FDI benefits consumers when the firms compete in quantities but FDI harms them when firms compete in prices.

While FDI may affect the home country's consumers and firm differently, it almost always decreases the consuming country's welfare. The exception occurs only when the following three conditions hold simultaneously: (i) the goods are highly differentiated (so there is little strategic interaction); (ii) demand uncertainty is large relative to cost uncertainty or there is sufficiently small "local content" of inputs; and (iii) the firms compete in quantities. A high degree of product differentiation implies that the local firm is little affected by the foreign firm's access mode (production location) and that cost learning also has little or no effect on consumers. Thus, when these three conditions are met, FDI affects the consuming country's

\footnotetext{
${ }^{6}$ Three conditions must hold simultaneously for the home firm actually to benefit: (i) cost uncertainty is sufficiently great (but not too great to prevent the foreign firm from choosing FDI) or local content is sufficiently large; (ii) the goods are relatively undifferentiated; and (iii) the firms compete in prices. Thus, for example, even if the firms compete in prices and the goods are of any degree of product differentiation, if the demand and cost uncertainty are of the same magnitude, then the local firm is always harmed when the foreign firm prefers FDI.
} 
welfare primarily through demand learning, which is positive with quantity competition.

We close the introduction by noting that the information structure here bears some resemblance to that in the well-known "information sharing" literature. The information sharing literature asks if it is profitable for a firm to commit to share with its rivals what the firm will learn in the future (for a review see Vives 1990 or more recently Creane 2007). In this literature, the type of information to be learned is fixed, e.g., does the firm benefit from sharing information about its private cost parameter? In contrast, here the type of information to be learned changes as the access mode switches from exporting to FDI, e.g., does the firm benefit from its learning about a common parameter instead of a private parameter? Indeed, to eliminate any aspect of "information sharing," we purposely assume that the home country rival knows the foreign firm's cost regardless of the foreign firm's access mode so that "sharing" its information is not an option for the foreign firm (unlike in Creane and Miyagiwa 2008). The foreign firm's decision only changes the type of cost information. For completeness, however, we outline, in section (3.6), what occurs if instead the "information sharing" effect is included. ${ }^{7}$ We find that this alternative information structure does not qualitatively change our results. Thus, our final result is that the "learning correlation" effect appears to be stronger than the "information sharing" effect.

The remainder of the paper is organized in four sections. In the next section we present the main modeling assumptions. We then examine the outcomes when the firms compete in quantities (Section 3) and then prices (Section 4). Section 5 concludes and briefly considers additional extensions.

\section{Environment}

A foreign firm (firm $f$ ) competes with a home firm (firm $h$ ) in the home market producing differentiated goods in quantities $q_{f}$ and $q_{h}$, respectively. The home firm always produces at home but the foreign firm can locate in the foreign country $(F)$ or the home country $(H)$.

\footnotetext{
${ }^{7}$ There, we assume that the home firm learns the foreign firm's cost only if the latter chooses FDI. In other words, choosing FDI is tantamount to "sharing" its cost information with the home firm.
} 
For the foreign firm there is set-up (fixed) $\operatorname{cost} s_{N}, N=F, H$ depending on its plant location. Marginal costs are constant, and depend partially on the location of production and partially on the extent to which input supply is internationally integrated (so firms face common world input prices). Let $x$ represent the fraction of costs from internationally integrated inputs and $(1-x)$ from local inputs. ${ }^{8}$ To focus on the issue at hand, we assume that these fractions are independent of location of production. Let $c_{j, N}, j=f, h$ denote the location-specific marginal cost for firm $j$ and $c_{I}$ denote the internationally integrated marginal cost. Then, the home firm's marginal cost is $x c_{I}+(1-x) c_{h, H}$. In contrast, the foreign firm's marginal cost equals $x c_{I}+(1-x) c_{f, N}$, depending on the choice of production location. Note that two firms' costs are identical when all inputs are internationally procured $(x=1)$. More importantly, the firms costs are also identical (for all $x$ ) when the foreign firm locates its production in the home country because there they face the same prices for locally procured inputs, i.e., $c_{f, H}=c_{h, H} \equiv c_{H}$.

Consumers in the home market are modeled, following Vives' (1984) model of learning in strategic competition, as a continuum of identical agents with separable, linear utility in the numeraire good and quadratic preferences for the differentiated goods:

$$
U\left(q_{f}, q_{h}\right)=\alpha\left(q_{f}+q_{h}\right)-(1 / 2)\left(q_{f}^{2}+2 \delta q_{f} q_{h}+q_{h}^{2}\right), \alpha>0,1 \geq \delta>0
$$

where $\delta \in[0,1]$ is a measure of product substitutability. Given prices $p_{f}$ and $p_{h}$, the consumer chooses $q_{f}$ and $q_{h}$ to maximize

$$
\alpha\left(q_{f}+q_{h}\right)-(1 / 2)\left(q_{f}^{2}+2 \delta q_{f} q_{h}+q_{h}^{2}\right)-p_{f} q_{f}-p_{h} q_{h}
$$

We model the interaction between the firms in three stages. In stage one the foreign firm choose a plant location $(F$ or $H)$ and hence a mode of access to home country consumers (export or FDI). The home firm has a plant in the home country. In stage two, nature

\footnotetext{
${ }^{8}$ An alternative interpretation is that production uses only locally procured inputs but that only fraction $(1-\mathrm{x})$ of cost is susceptible to local shocks. In either interpretation fraction $(1-\mathrm{x})$ represents the extent to which costs and so learning between firms are correlated.
} 
draws values for the intercept $\alpha$ and $\operatorname{costs}, c_{j, H}, c_{j, F}$ and $c_{I}$. If the foreign firm chose FDI in stage one, both firms observe all the choices Nature has made. If the foreign firm chose exporting, the home firm still observes all but the foreign firm can observe only $c_{j, F}$ and $c_{I}{ }^{9}$ Let $E[\alpha]=\bar{\alpha}$ and $\operatorname{Var}[\alpha]=\sigma_{\alpha}$ and similarly $E\left[c_{j, N}\right]=\bar{c}_{j, N}$ and $\operatorname{Var}\left[c_{j, N}\right]=\sigma_{j, N}^{2}$. In stage three, given the foreign firm's location and all cost realizations, the firms compete in quantities or prices in the home market.

We make two additional assumptions to simplify the exposition. First, we assume that country-specific costs have the same variance, i.e., $\operatorname{Var}\left[c_{j}, N\right]=\sigma_{c}^{2}$, although we will keep subscripts to make clear the source of different effects. Once the derivations are presented, the straightforward implications of relaxing this assumption will become clear to the reader. Second, we assume that $\operatorname{Var}\left[c_{I}\right]=0$, i.e., the value of $c_{I}$ is fixed. This does not affect our results because the international content is independent of location, and so the variance nets out in the analysis.

\section{Quantity Competition}

\subsection{Benchmark (model without learning)}

To help understand the role that learning plays in the foreign firm's access mode choice, we determine as a benchmark the equilibrium in which neither firm learns (this is also equivalent to when there is no uncertainty, i.e., $\left.\sigma_{(\cdot)}^{2}=0\right)$. As a result, there is no information effects from the location decision. Specifically, in this subsection neither firm learns about any cost shock before making their output choices. As we will see, this will result in the usual Cournot equilibrium. To derive the equilibrium we first characterize the third stage, and then work back to each previous stage. From consumers maximizing their utility (the first-order conditions on (1)), firm $j$ faces inverse demand $p_{j}=\alpha-q_{j}-\delta q_{k}, j \neq k$. If the foreign firm

\footnotetext{
${ }^{9}$ As noted in the introduction, this allows the foreign firm's access choice to be free of the "information sharing" effect. More importantly, the results do not qualitatively change with the obvious variation in the information structure of having the home firm not known the foreign firm's cost when the foreign firm chooses exporting, which we outline in 3.6.
} 
chooses to export (letting the superscript $X$ indicate export and $N L$ indicate no learning), it chooses $q_{f}$ to maximize expected profit

$$
\begin{aligned}
E\left[\pi_{f}^{X, N L}\right] & =E\left[\alpha-q_{f}-\delta q_{h}-\left(x c_{I}+(1-x) c_{f, F}\right)\right] q_{f}-s_{F} \\
& =\left[\bar{\alpha}-q_{f}-\delta q_{h}-\left(x c_{I}+(1-x) \bar{c}_{f, F}\right)\right] q_{f}-s_{F}
\end{aligned}
$$

where the second equality follows from the fact that the intercept and cost enter in linearly in the expectation. Likewise, the home firm's expected profit equals

$$
E\left[\pi_{h}^{N L}\right]=\left[\bar{\alpha}-q_{h}-\delta q_{f}-\left(x c_{I}+(1-x) \bar{c}_{h, H}\right)\right] q_{h} .
$$

Using (2) and (3) one can obtain the Cournot equilibrium outputs. Substituting them, we obtain the Cournot equilibrium profits

$$
E\left[\pi_{f}^{X, N L}\right]=\frac{\left[\bar{\alpha}(2-\delta)-2\left(x c_{I}+(1-x) \bar{c}_{f, F}\right)+\delta\left(x c_{I}+(1-x) \bar{c}_{h, H}\right)\right]^{2}}{\left(4-\delta^{2}\right)^{2}}-s_{F}
$$

If instead the foreign firm chooses FDI, the same logic yields

$$
E\left[\pi_{f}^{F D I, N L}\right]=\frac{\left[\bar{\alpha}-\left(x c_{I}+(1-x) \bar{c}_{h}\right)\right]^{2}}{(2+\delta)^{2}}-s_{H},
$$

where $c_{H}$ denote the common home marginal cost, i.e., $c_{f, H}=c_{h, H} \equiv c_{H}$.

Clearly, whether the foreign firm would choose exporting or FDI depends on the difference of $\left[\pi_{f}^{F D I, N L}\right]-\left[\pi_{f}^{X, N L}\right]$, and what we have with no learning is the classic proximityconcentration trade-off: the decision depends only on the values of $\left\{\bar{c}_{f, F}, \bar{c}_{f, H}, \bar{c}_{h, H}, s_{F}, s_{H}\right\}$. Note that the variance of the uncertainty parameters does not enter into the calculus. It should also be clear that

Remark 1 Suppose neither firm learns demand and cost shocks. If $\bar{c}_{f, F}=\bar{c}_{f, H}$ and $s_{F}=$ $s_{H}=0$, then the foreign firm is indifferent between exporting and FDI: $E\left[\pi_{f}^{N L, F D I}\right]=$ $E\left[\pi_{f}^{N L, X}\right]$. 
Note that the same would hold true if there were no uncertainty, i.e., $\sigma_{(\cdot)}^{2}=0$. To highlight the effect of learning on FDI decisions, we remove the effects of the proximity-concentration tradeoff from the model in the remainder of the paper; that is, we assume that $\bar{c}_{f, F}=\bar{c}_{f, H}=$

$\bar{c}_{h, H} \equiv \bar{c}$ and that $s_{F}=s_{H}$. Therefore, let $\bar{\pi} \equiv E\left[\pi_{f}^{N L, F D I}\right]=E\left[\pi_{f}^{N L, X}\right]$ denote the expected profit with no learning (or no uncertainty). Having developed the benchmark model without learning, we now turn to derive the equilibrium with learning.

\subsection{Third stage with learning}

In the third stage, the foreign firm has already made its location choice (exporting or FDI) and the demand and the cost shocks have been realized. There are two subgames to consider, depending on the foreign firm's choice of access mode (production location).

\subsubsection{Foreign firm exports}

If it exports, the foreign firm learns its own cost $\left(c_{f, F}\right)$, but does not learn the home market demand intercept $(\alpha)$ nor the rival's cost realization $\left(c_{h, H}\right)$. Thus, it chooses $q_{f}$ to maximize the expected profit

$$
E\left[\alpha-q_{f}-\delta q_{h}\left(\alpha, c_{h, H}\right)-\left(x c_{I}+(1-x) c_{f, F}\right)\right] q_{f}
$$

The first-order condition can be arranged to yield the best-response function

$$
q_{f}\left(c_{f, F}\right)=E\left[\alpha-\left(x c_{I}+(1-x) c_{f, F}\right)-\delta q_{h}\left(\alpha, c_{h, H}\right)\right] / 2 .
$$

In contrast, having complete information, the home firm chooses $q_{h}$ to maximize

$$
\left[\alpha-q_{h}-\delta q_{f}\left(\alpha, c_{f, F}\right)-\left(x c_{I}+(1-x) c_{h, H}\right)\right] q_{h}
$$


The first-order condition gives us the best-response function

$$
q_{h}\left(\alpha, c_{h, H}\right)=\left[\alpha-\left(x c_{I}+(1-x) c_{h, H}\right)-\delta q_{f}\left(c_{f, F}\right)\right] / 2
$$

From (4) and (5) and taking the foreign firm's expectation of the home firm's choice (5), we obtain the following Bayesian-Nash equilibrium outputs:

$$
\begin{gathered}
q_{f}^{X}=\frac{\bar{\alpha}(2-\delta)-2\left(x c_{I}+(1-x) c_{f, F}\right)+\delta\left(x c_{I}+(1-x) \bar{c}_{h, H}\right)}{4-\delta^{2}} \\
q_{h}^{X}=\frac{\alpha(2-\delta)-2\left(x c_{I}+(1-x) c_{h, H}\right)+\delta\left(x c_{I}+(1-x) c_{f, F}\right)}{4-\delta^{2}}+\frac{\delta^{2}}{2} \frac{\alpha-\bar{\alpha}+(1-x)\left(c_{h, H}-\bar{c}_{h, H}\right)}{4-\delta^{2}}
\end{gathered}
$$

Third-stage equilibrium profits then are

$$
\begin{aligned}
& \pi_{f}^{X}=\left(\alpha-q_{f}^{X}-\delta q_{h}^{X}-\left(x c_{I}+(1-x) c_{f, F}\right)\right) q_{f}^{X} \\
& \pi_{h}^{X}=\left(\alpha-q_{h}^{X}-\delta q_{f}^{X}-\left(x c_{I}+(1-x) c_{h, H}\right)\right) q_{h}^{X}
\end{aligned}
$$

Note that the foreign firm's profit is linear in demand intercept and the home firm's cost shocks since they do not enter $q_{f}^{X}$.

\subsubsection{Foreign firm chooses FDI}

If the foreign firm chooses FDI, both firms know the demand and (now common) cost shocks and hence play a game of complete information. The usual calculus yields the following symmetric Nash equilibrium outputs:

$$
q_{j}^{F D I}=\frac{\alpha(2-\delta)-2\left(x c_{I}+(1-x) c_{j, H}\right)+\delta\left(x c_{I}+(1-x) c_{k, H}\right)}{4-\delta^{2}}=\frac{\alpha-\left(x c_{I}+(1-x) c_{H}\right)}{2+\delta} .
$$

Firm $j$ 's third-stage equilibrium profit is given by

$$
\pi_{j}^{F D I}=\left(\alpha-q_{j}^{F D I}-\delta q_{k}^{F D I}-\left(x c_{I}+(1-x) c_{j, H}\right)\right) q_{j}^{F D I}
$$


These calculations fully characterize the two third-stage games. In stage two Nature moves, revealing information to the firms according to the foreign firm's mode selection. We now proceed to the first stage.

\subsection{First stage}

To simplify exposition it is useful to exploit the fact that, as the shocks enter the profit expression linearly and we have assumed equal means, the expected output in the first stage is the same across access mode (production location) decisions; that is, $E\left[q_{j}^{F D I}\right]=E\left[q_{j}^{X}\right]{ }^{10}$ Define this "mean" output as

$$
\bar{q}_{j}^{(\cdot)} \equiv \frac{\bar{a}(2-\delta)-2\left(x \bar{c}_{I}+(1-x) \bar{c}_{j, N}\right)+\delta\left(x \bar{c}_{I}+(1-x) \bar{c}_{k, N}\right)}{4-\delta^{2}} .
$$

Note that $\bar{q}_{j}^{(\cdot)}$ is also a firm's output if it did not learn any of the shocks (Section (3.1)). Further, since expected marginal costs are equal, expected outputs are the same across firms; that is, $\bar{q}_{j}^{(\cdot)}=\bar{q}_{k}^{(\cdot)} \equiv \bar{q}$. Recall also from Section $(3.1)$ that $\pi_{j}^{X}(\bar{q})=\pi_{j}^{F D I}(\bar{q})$ : the profit evaluated at the expected cost are also equal across access mode choices and firm and that we have denoted this common profit by $\bar{\pi}$.

We now compute the expected profits. We start with the case that the foreign firm exports (and so by assumption the home firm observes the foreign firm's cost, but the foreign firm does not observe the home firm's cost). Taking the expectation of $\pi_{f}^{X}(6)$ yields

$$
E\left[\pi_{f}^{X}\right]=\bar{\pi}+\frac{4(1-x)^{2}}{\left(4-\delta^{2}\right)^{2}} \sigma_{f, F}^{2}
$$

The first term in (8) is the foreign firm's expected profit when it does not learn (and would have set output $\bar{q}_{f}$ ). The second term reflects the value to the foreign firm from both firms learning the foreign firm's cost. Two effects determine the coefficient on variance. The first is the classic value from learning: because the foreign firm adjusts its output upon learning its cost shock, its profit, given that cost realization, is greater than when the foreign firm

\footnotetext{
${ }^{10}$ See Qiu (1994) for a clear demonstration and intuition of these results.
} 
does not learn (and so cannot adjust its output from $\bar{q}_{f}$ ). Hence, its expected profit with learning is greater than expected profit without learning $(\bar{\pi})$. Specifically, if the home firm did not learn the foreign firm's cost, then the foreign firm's expected profit would be:

$$
E\left[\pi_{f}^{X, N L h}\right]=\bar{\pi}+\frac{(1-x)^{2}}{4} \sigma_{f, F}^{2}
$$

with the superscript $N L h$ indicating no learning by the home firm.

The coefficient on variance in (9) is smaller than the coefficient in (8) and the difference comes from the second effect (home firm learning), that is, that the home firm also learns the foreign firm's cost shock and reacts to it. To understand how the learning by the home firm affects the foreign firm, suppose, for example, that the foreign firm draws a lower-thanaverage cost. From the envelope theorem, the direct effect is to increase the foreign firm's profit margin, $\left(\alpha-q_{f}-\delta q_{h}-\left(x c_{I}+(1-x) c_{f, F}\right)\right)$, by $(1-x) d c_{f, F}$ given the home firm's output (this effect shows up in (9)). However, there is a second effect: observing the foreign firm having low cost, the home firm contracts its output, which further increases the foreign firm's profit margin. Thus, the home firm's learning amplifies the effect of drawing a lower cost. The same logic applies when the foreign firm draws a higher-than-average cost; the foreign firm's profit margin decreases more when the home firm learns. Thus, the home firm's learning of the foreign firm's cost realization generate an effect akin to a mean-preserving spread on the cost distribution of the foreign firm, which is beneficial because its profit is convex in cost. ${ }^{11}$

Equation (8) merits two further remarks. First, the the home learning effect diminishes as $\delta$ diminishes; that is, as the goods become more differentiated (smaller $\delta$ ), the home firm's output response generates less variability in the foreign firm's profit margin, decreasing the foreign firm's expected profit. Second, since the foreign firm does not learn demand or the home firm's cost realization, those shocks do not introduce variance into the foreign firm's

\footnotetext{
${ }^{11}$ The total effect of a unit cost change to the foreign firm (i.e., both the foreign firm's cost change and the change in the home firm's output) on the foreign firm's profits therefore equals $-\left[1+\left(\delta^{2} /\left(4-\delta^{2}\right)\right](1-x)=\right.$ $-4(1-x) /\left(4-\delta^{2}\right)$ which is greater in magnitude than $-(1-x)$, so the coefficient of the variance term is $4(1-x)^{2} /\left(4-\delta^{2}\right)^{2}$. This is the reason why Cournot firms agree to information sharing contracts on their cost (see, e.g., Gal-Or 1986).
} 
expected profit expression in (8).

Consider now the case in which the foreign firm chooses FDI. Then, since both firms know home demand and face the same cost shock specific to the home country, they have the identical expected profit:

$$
E\left[\pi_{i}^{F D I}\right]=\bar{\pi}+\frac{(2-\delta)^{2}}{\left(4-\delta^{2}\right)^{2}} \sigma_{\alpha}^{2}+\frac{(1-x)^{2}(2-\delta)^{2}}{\left(4-\delta^{2}\right)^{2}} \sigma_{H}^{2},
$$

where the firm indication on the cost variance has been dropped as $\sigma_{f, H}^{2}=\sigma_{h, H}^{2} \equiv \sigma_{H}^{2}$.

For the foreign firm, its profit from FDI (10) differs from its profit from exporting (8) in two respects. First, with FDI, since the foreign firm now learns and adjusts to demand shocks, its profit is convex in the demand intercept, implying that the foreign firm values demand information. This is reflected by the positive coefficient on $\sigma_{\alpha}^{2}$ in (10).

Second, the coefficient of cost variance $\sigma_{H}^{2}$ in (10) differs from that of $\sigma_{f, F}^{2}$ in (8) because of the correlation of learning alluded to earlier: by locating in the home country the foreign firm learns the home firm's cost, but also faces the same cost shocks that the home firm does: the information has gone from being about a private parameter to being about a common parameter. To understand the implication, suppose that the foreign firm draws a lower-than-average cost $\left(d c_{f, H}\right)$. Both with FDI and with exporting, the direct effect of this lower cost is to, fixing the home firm's output, increase the foreign firm's profit margin $\left(\alpha-q_{f}-\delta q_{h}-\left(x c_{I}+(1-x) c_{f, H}\right)\right.$ by $(1-x) d c_{f, H}$. With FDI, however, the home firm also has drawn a lower cost and expands its output, which decreases the foreign firm's profit margin, given the cost shock; in contrast, with exporting the home firm would have, instead, contracted its output. Thus, the second effect depends on the access mode. Calculations show that this second effect decreases the foreign firm's profit margin by $(\delta(1-x) /(2+\delta)) d c_{f, H}$. In net, these two effects change the profit margin by $(2(1-x) /(2+\delta)) d c_{f, H}$, which is smaller in magnitude as compared with the export case. ${ }^{12}$ Similarly, when the firms draw a higher-

\footnotetext{
${ }^{12}$ Since its cost shock effect is -1 , the net effect of a unit cost change (home firm response plus the direct cost change) equals $\delta /(2+\delta)-1=-2 /(2+\delta)$, which is smaller in magnitude than -1 . As $-2 /(2+\delta)=$ $-2(2-\delta) /\left(4-\delta^{2}\right)$ we have the coefficient of $(2-\delta)^{2} /\left(4-\delta^{2}\right)^{2}$ on the variance term.
} 
than-average cost, the foreign firm's profit margin decreases by a smaller amount than in the exporting case. Thus, correlation of cost shocks with learning generates an effect similar to a mean-preserving contraction on the cost distribution, which is harmful to the foreign firm, given convexity of profit.

\subsection{The access mode choice for the foreign firm}

We are now in a position to address our main issue. The foreign firm chooses FDI whenever it is more profitable than exporting or if:

$$
E\left[\pi_{f}^{F D I}\right]-E\left[\pi_{f}^{X}\right]=\frac{(2-\delta)^{2}}{\left(4-\delta^{2}\right)^{2}} \sigma_{\alpha}^{2}+\frac{(1-x)^{2}(2-\delta)^{2}}{\left(4-\delta^{2}\right)^{2}} \sigma_{H}^{2}-\frac{4(1-x)^{2}}{\left(4-\delta^{2}\right)^{2}} \sigma_{f, F}^{2}>0
$$

The second and third terms sum to less than zero under the assumption that the variances on the country-specific shocks are identical; $\sigma_{H}^{2}=\sigma_{f, F}^{2}$ (recall that $\sigma_{i, F}^{2}=\sigma_{c}^{2}$ ). Thus, the foreign firm's decision depends on whether the value from learning about the market demand is relatively greater than the harm from learning correlation. Using the common cost variance $\sigma_{c}^{2}$ in (11), we obtain:

Proposition 1 When firms compete in quantities, FDI is more profitable than exporting for the foreign firm (A) if the demand uncertainty is sufficiently greater than the cost uncertainty, $(B)$ if the goods are sufficiently differentiated, or $(C)$ if production costs are not too locally dependent. That is, FDI is more profitable if and only if

$$
\sigma_{\alpha}^{2} \geq \frac{(1-x)^{2} \delta(4-\delta)}{(2-\delta)^{2}} \sigma_{c}^{2}
$$

When the goods are perfect substitutes $(\delta=1)$ the condition in Proposition 1 becomes $\sigma_{\alpha}^{2} \geq 3(1-x)^{2} \sigma_{c}^{2}$. As the goods become more differentiated (or $\delta$ decreases), the RHS of (12) decreases: FDI becomes more attractive. This has both a demand-side and a cost-side explanation. On the demand side, a higher-than-average demand induces the home firm to expand output $q_{h}$, dampening the net increase in the foreign firm's price-cost margin 
$\left(\alpha-q_{f}-\delta q_{h}-\left(x c_{I}+(1-x) c_{f, H}\right)\right)$. However, as the expression for the price-cost margin makes clear, a smaller $\delta$ mitigates the dampening effect. The same logic applies for lowerthan-average demand, yielding a result akin to a mean-preserving spread on the demand distribution as the goods become more differentiated (smaller $\delta$ ), which benefits the foreign firm. Thus, demand information is more valuable, the more differentiated the goods. The logic on the cost-side works similarly. As the discussion following (10) indicates, a decrease in $\delta$ mitigates the effect of a mean-preserving contraction in the cost distribution, making FDI more attractive. Thus, both on the demand and on the cost side a decrease in $\delta$ makes FDI more profitable to the foreign firm.

As for the dependency of production on local inputs, as cost becomes more location dependent (a decrease in $x$ ), the correlation effect worsens, making FDI less attractive. Put differently, as input markets become more globalized (an increase in $x$ as inputs are sourced from the global market rather than from the local market), FDI becomes more attractive to the foreign firm. This has an interesting implication. As the input market becomes more globally integrated (partly because of FDI in the input markets) and input cost depend less on location choice as the input is sourced from the global supplier rather than locally, the correlation effect diminishes encouraging more FDI. Thus, input FDI begets final good FDI, which may be a contributing factor as to why FDI has been growing at a greater rate than GDP and trade.

\subsection{Home country welfare}

We next examine the effect of FDI on home firm profit, consumer surplus and home country welfare (home firm profit plus consumer surplus).

We begin with home firm profit. Since the home firm always learns and responds to

demand and cost realizations when the foreign firm exports, these three shocks (demand, home cost, foreign cost) together with learning introduce three variance terms into the home 
firm's expected profit:

$$
E\left[\pi_{h}^{X}\right]=\bar{\pi}+\frac{1}{4} \sigma_{\alpha}^{2}+\frac{(1-x)^{2}}{4} \sigma_{h, H}^{2}+\frac{(1-x)^{2} \delta^{2}}{\left(4-\delta^{2}\right)^{2}} \sigma_{f, F}^{2}
$$

Though we assume that $\sigma_{h, H}^{2}=\sigma_{f, F}^{2}$ we have kept the subscripts to clarify the role of various cost shocks in the location decision.

When the foreign firm chooses FDI, profits are identical across firms, so (10) also represents the home firm's expected profit. Then the relative effect of FDI on the home firm's profits is given by

$$
\begin{aligned}
E\left[\pi_{h}^{F D I}\right]-E\left[\pi_{h}^{X}\right]=- & \frac{\delta(4+\delta)(2-\delta)^{2}}{4\left(4-\delta^{2}\right)^{2}} \sigma_{\alpha}^{2} \\
& \quad-\frac{\delta(1-x)^{2}(4+\delta)(2-\delta)^{2}}{4\left(4-\delta^{2}\right)^{2}} \sigma_{H}^{2}-\frac{4(1-x)^{2} \delta^{2}}{4\left(4-\delta^{2}\right)^{2}} \sigma_{f, F}^{2}
\end{aligned}
$$

All the terms in (13) are negative, and hence FDI makes the home firm worse off.

Proposition 2 FDI harms the home firm.

The intuition behind Proposition 2 is straightforward. If the foreign firm chooses FDI, the home firm loses its advantage in demand information and is also harmed by the correlation effect. However, a key aspect is that even if the home firm had no informational advantage on demand, it would oppose FDI because of the correlated learning (i.e., even if $\sigma_{\alpha}^{2}=0$, the RHS of (13) is negative). Finally, no matter how internationally integrated the input markets become (an increase in $x$ ), the home firm is still harmed by FDI because of the loss of the demand advantage.

Turning to consumers, substituting the derived demands into consumer surplus (1) yields

$$
\frac{q_{f}^{2}}{2}+\delta q_{f} q_{h}+\frac{q_{h}^{2}}{2}
$$

Because consumers make purchases after observing prices, a consumer is able to adjust their consumption between the two goods the firms produce and the numeraire good; i.e., when 
the price is high for a good, the harm is mitigated as the consumer substitutes away from it to the other goods, and when the price is low they can buy more of it. ${ }^{13}$ As a result, consumer surplus is convex in the firms' output, that is, consumer surplus is increasing in output variability.

Using equilibrium quantities in the third stage, we can calculate expected consumer surplus under exporting and FDI. ${ }^{14}$ Since expected outputs are the same with either mode, mean consumer surplus (that is, consumer surplus evaluated at expected cost and demand) is the same. Denote this mean consumer surplus $\overline{C S}$. Substituting the equilibrium outputs $q_{i}^{X}$ into (14) and taking the expectation yields expected consumer surplus when the foreign firm exports:

$$
E\left[C S^{X}\right]=\overline{C S}+\frac{1}{8} \sigma_{\alpha}^{2}+\frac{(1-x)^{2}}{8} \sigma_{h, H}^{2}+\frac{(1-x)^{2}\left(4-3 \delta^{2}\right)}{2\left(4-\delta^{2}\right)^{2}} \sigma_{f, F}^{2}
$$

If the foreign firm chooses FDI, then there is only one variance term for the cost shock, subscripted $H: \sigma_{f, H}^{2}=\sigma_{h, H}^{2}=\sigma_{H}^{2}$. Using $q_{i}^{F D I}$ in (14) and taking the expectation yields expected consumer surplus with FDI:

$$
E\left[C S^{F D I}\right]=\overline{C S}+\frac{1+\delta}{(2+\delta)^{2}} \sigma_{\alpha}^{2}+\frac{(1-x)^{2}(1+\delta)}{(2+\delta)^{2}} \sigma_{H}^{2}
$$

The relative effect of FDI on consumer surplus is

$$
\begin{gathered}
E\left[C S^{F D I}\right]-E\left[C S^{X}\right]=\frac{\left(4+4 \delta-\delta^{2}\right)(2-\delta)^{2}}{8\left(4-\delta^{2}\right)^{2}} \sigma_{\alpha}^{2}+\frac{(1-x)^{2}\left(4+4 \delta-\delta^{2}\right)(2-\delta)^{2}}{8\left(4-\delta^{2}\right)^{2}} \sigma_{H}^{2} \\
-\frac{4(1-x)^{2}\left(4-3 \delta^{2}\right)}{8\left(4-\delta^{2}\right)^{2}} \sigma_{f, F}^{2}
\end{gathered}
$$

Analyzing (15), we see that FDI can potentially harm home consumers. However, if the goods are sufficiently close substitutes, then FDI always benefits home consumers. Specifically, if $\delta \geq 2\left(2-3^{1 / 2}\right) \approx(1 / 2)$, then the sum of the last two terms on the RHS of (15) is

\footnotetext{
${ }^{13}$ Recall that the Walrasian auctioneer in the Cournot model sets the prices to clear the market given the firms' output, i.e. the prices so that the consumers consume the total amount brought to market.

${ }^{14}$ See Schlee (2008) for analysis of expected consumer surplus under other assumptions on preferences.
} 
positive, so (15) is positive: FDI is always beneficial to consumers. That is, a necessary but not sufficient condition for FDI to harm consumers is that $\delta<2\left(2-3^{1 / 2}\right)$. To understand how FDI can harm consumers, note that consumers are hurt when the foreign firm chooses FDI because they no longer have the opportunity to buy more of the foreign good when foreign cost is low. However, as the goods become closer substitutes ( $\delta$ increases) this harm becomes relatively smaller because the correlated effect on costs becomes relatively larger (the middle term on the RHS of (15). For $\delta \geq 2\left(2-3^{1 / 2}\right)$ the coefficient on $\sigma_{H}^{2}$ becomes greater than that on $\sigma_{f, F}^{2}$. On the other hand, consumers benefit from FDI because the foreign firm better responds to demand conditions: producing more output when the consumers value the product more (high demand) and less output when they value it less. As the goods become closer substitutes ( $\delta$ increases) this benefit becomes stronger. Thus, FDI could harm consumers if demand uncertainty is small relative to cost uncertainty. Finally, as the world becomes more integrated ( $x$ increases), consumers are more likely to benefit from FDI.

Although the above discussion might imply that the effect of FDI on consumer welfare is indeterminate, the effect is unambiguous when the foreign firm would choose choose FDI over exporting. That is, FDI benefits home consumers if FDI is more profitable to the foreign firm than exporting. For brevity we henceforth denote FDI satisfying the above qualification simply as profitable FDI.

Proposition 3 Profitable FDI increases expected home consumer surplus.

Proof. From (15) FDI increases consumer surplus whenever

$$
\sigma_{\alpha}^{2} \geq \frac{\delta^{2}(1-x)^{2}\left(4-8 \delta+\delta^{2}\right)}{(2-\delta)^{2}\left(4+4 \delta-\delta^{2}\right)} \sigma_{c}^{2}
$$

Since

$$
\frac{\delta(4-\delta)}{(2-\delta)^{2}} \geq \frac{\delta^{2}\left(4-8 \delta+\delta^{2}\right)}{(2-\delta)^{2}\left(4+4 \delta-\delta^{2}\right)}
$$


condition (12) implies

$$
\sigma_{\alpha}^{2} \geq \frac{\delta(1-x)^{2}(4-\delta)}{(2-\delta)^{2}} \sigma_{c}^{2} \geq \frac{\delta^{2}(1-x)^{2}\left(4-8 \delta+\delta^{2}\right)}{(2-\delta)^{2}\left(4+4 \delta-\delta^{2}\right)}
$$

Thus, if FDI is profitable to the foreign firm, home consumer surplus increases with FDI.

FDI could harm consumers when demand uncertainty is relatively small. However, by Proposition 1 this is exactly when the foreign firm would prefer exporting to FDI. In fact, it is even possible that the foreign firm would prefer exporting even though consumers prefer FDI. This does not imply that any profitable FDI is beneficial to consumers. If FDI decisions are distorted by, for example, subsidies or tax-holiday programs, then FDI could harm consumers even though it benefits the foreign firm. Finally, notice that the result does not depend on how internationally integrated the input market is $(x)$.

We turn next to the effect of FDI on home welfare, which comprises home profit and consumer surplus: $W \equiv \pi_{h}+C S$. The effect is not obvious because when it is profitable to the foreign firm, FDI benefits home consumers but harms the home firm. Combining (13) and (15) the relative welfare impact of FDI is:

$$
E\left[W^{F D I}\right]-E\left[W^{X}\right]=\frac{(2-3 \delta)(2-\delta)}{8\left(4-\delta^{2}\right)} \sigma_{\alpha}^{2}+\frac{(1-x)^{2}(2-3 \delta)(2-\delta)}{8\left(4-\delta^{2}\right)} \sigma_{H}^{2}-\frac{4(1-x)^{2}}{8\left(4-\delta^{2}\right)} \sigma_{f, F}^{2} .
$$

Examination of (17) shows that FDI reduces home country welfare if (i) the goods are sufficiently undifferentiated or (ii) the goods are sufficiently differentiated and either demand uncertainty is relatively small or local production is sufficiently large. If the goods are close enough substitutes, i.e., $\delta>2 / 3$, then (17) is clearly negative, so FDI yields lower welfare than exporting. On the other hand, if $\delta<2 / 3$, the first two terms on the right-hand side of (17) are positive while the third is negative. Then demand uncertainty needs to be relatively small for (17) to be negative. However, if the demand uncertainty is too small the foreign firm does not choose FDI by (12). Straightforward manipulations of (17) shows that there is still a range of uncertainty in which profitable FDI harms the home country for $\delta<2 / 3$. 
Proposition 4 Profitable FDI reduces home welfare when either the goods are close enough substitutes, or, demand uncertainty is not too large relative to cost uncertainty and production costs are sufficiently locally dependent:

$$
\begin{aligned}
& \text { (A) } \delta>\frac{2}{3} \\
& \text { (B) } \delta<\frac{2}{3} \text { and } \sigma_{\alpha}^{2} \leq \delta \frac{(1-x)^{2}(8-3 \delta)}{(2-\delta)(2-3 \delta)} \sigma_{c}^{2} .
\end{aligned}
$$

In the first case $(\delta>2 / 3)$, as the goods become closer substitutes the home firm loses more of its informational advantage from FDI and its profit falls as a result. Also, home consumers gain less from the foreign firm learning demand because of the strategic response of the home firm (e.g., when demand is high the home firm's increase in output reduces the magnitude of the foreign firm's increase in output). Similarly, as the goods are closer substitutes the home firm is harmed more by the correlation of its cost with the foreign firm's cost. In the second case $(\delta<2 / 3)$, when the goods are more differentiated, the logic is reversed and home welfare increases, unless cost uncertainty is sufficiently large so that home consumer gain very little (Proposition 3), but not so large that the foreign firm would not choose FDI (Proposition 1). In the extreme case of independent goods ( $\delta=0$, so the empty set for $\sigma_{\alpha}^{2}$ ), there is only the demand learning effect by the foreign firm, which benefits home consumers and does not harm the home firm.

\subsection{Other information structure}

In the preceding analysis we assumed that the home firm always observes the foreign firm's cost while the foreign firm does not observe the home firm's cost when it exports. As discussed in Section 2, there is another information structure that is also quite plausible: No firms observe the rival's cost when exporting is chosen. Straightforward calculations show that this alternative produces only secondary effects so our results are qualitatively unaffected. That is, the correlation effect (i.e., switching from learning about a private parameter to learning about a common parameter) is significantly greater than any effect 
from the initial information structure for the home firm. For example, if the goods are perfect substitutes $(\delta=1)$, then the foreign firm will still choose FDI only if the demand uncertainty is greater than the cost uncertainty. Likewise, profitable FDI still benefits home consumers, harms the home firms, and increases the home country welfare, unless $\delta$ is sufficiently low (for the case of equal variances the critical $\delta$ is almost identical).

\section{Price Competition}

Oftentimes, in models of strategic competition the results critically turn on the type of competition. Therefore, in this section we check the robustness of our results under price competition. The main finding is that, surprisingly enough, almost all of the principal results from quantity competition carry over intact to price competition; namely, the incentive to choose FDI and the likelihood that the home firm is harmed by FDI is only slightly weakened while the likelihood the home country is harmed is strengthened (i.e., it is harmed for a greater range of parameter values).

The derivations of these results follow the outline of Section 3. Using again the first-order conditions on (1), but now inverting, firm $j$ faces the following demand

$$
q_{j}=\frac{\alpha}{1-\delta}-\frac{p_{j}}{1-\delta^{2}}+\frac{\delta p_{k}}{1-\delta^{2}}, \delta \in(0,1), j \neq k .^{15}
$$

Calculations analogous to those in Section 3.1 show that with no learning the same result is obtain as with quantity competition: if expected costs are identical across locations, the foreign firm is indifferent as to its access mode (location decision). The no learning benchmark is the same as in Remark 1. We next analyze what occurs with learning.

\footnotetext{
${ }^{15}$ Note that demand is not defined with perfect substitutes $(\delta=1)$. However, this approach allows the most direct comparison between price and quantity competition (see Vives (1984)).
} 


\subsection{Third stage}

In the third stage each firm simultaneously sets price. Using (18), firm $j$ chooses $p_{j}$ to maximize

$$
E\left[\frac{\alpha(1-\delta)-p_{j}+\delta p_{k}}{1-\delta^{2}}\left(p_{j}-\left(x c_{I}+(1-x) c_{j, N}\right)\right)\right]
$$

From the first-order condition firm $j$ 's best response is

$$
p_{j}=\frac{1}{2}\left(E[\alpha](1-\delta)+\delta p_{k}+\left(x c_{I}+(1-x) c_{j, N}\right)\right)
$$

where the expectation of $\alpha$ depends on the firm's information. For reference it is again useful to first calculate the outcome when there is no uncertainty, i.e., each parameter equals its mean, which is the same if the firms do not learn. In such a case, the Nash equilibrium price is

$$
\bar{p}_{j} \equiv \frac{\bar{\alpha}\left(2-\delta-\delta^{2}\right)+2\left(x \bar{c}_{I}+(1-x) \bar{c}_{j, N}\right)+\delta\left(x \bar{c}_{I}+(1-x) \bar{c}_{k, N}\right)}{4-\delta^{2}}
$$

As the remainder of the derivations closely follows the steps from the previous section, the intermediate steps are omitted.

Suppose that the foreign firm exports. Then in stage three firms play a game of (asymmetric) incomplete information. Calculations yield the Bayesian-Nash equilibrium prices:

$$
\begin{gathered}
p_{f}^{X}=\frac{\alpha\left(2-\delta-\delta^{2}\right)+2\left(x c_{I}+(1-x) c_{f, F}\right)+\delta\left(x \bar{c}_{I}+(1-x) \bar{c}_{h, H}\right)}{4-\delta^{2}} \\
p_{h}^{X}=\frac{\alpha\left(2-\delta-\delta^{2}\right)+2\left(x c_{I}+(1-x) c_{h, H}\right)+\delta\left(x c_{I}+(1-x) c_{f, F}\right)}{4-\delta^{2}} \\
-\frac{\delta}{2} \frac{(\alpha-\bar{\alpha})\left(2-\delta-\delta^{2}\right)+\delta(1-x)\left(c_{h, H}-\bar{c}_{h, H}\right)}{4-\delta^{2}}
\end{gathered}
$$

In contrast, if the foreign firm chooses FDI, then firms have complete information in stage three. As a result, equilibrium prices are

$$
p_{j}^{F D I}=\frac{\alpha\left(2-\delta-\delta^{2}\right)+(2+\delta)\left(x c_{I}+(1-x) c_{h, H}\right)}{4-\delta^{2}}
$$


From (18) we calculate the quantity demanded of each good in the third stage for given demand shocks and equilibrium prices, and then realized profits and consumer surplus. With these calculations we can derive the expected profits, etc. in the first stage.

\subsection{First stage}

As in quantity competition, cost and demand shocks are linear and the expected costs are assumed equal across firms and access modes. Thus, in the first stage the expected price is the same regardless of the foreign firm's access mode choice. That is, in stage one (before

costs are realized), $E\left[p_{j}^{X}\right]=E\left[p_{j}^{F D I}\right]$, which equals the equilibrium price if there were no learning or zero variance (see subsection (3.1)). Define this "mean" price by $\bar{p}_{j}$. As outputs evaluated at the expected cost are equal across access modes and firms, so too are profits, denoted $\bar{\pi}$.

With exporting, substituting the expressions for $p_{h}^{X}$ and $p_{f}^{X}$ into the profit expression (19) and taking the expectation yields the foreign and home firm's expected profit

$$
\begin{aligned}
& E\left[\pi_{f}^{X}\right]=\bar{\pi}+\frac{(1-x)^{2}\left(2-\delta^{2}\right)^{2}}{\left(4-\delta^{2}\right)^{2}\left(1-\delta^{2}\right)} \sigma_{f, F}^{2} \\
& E\left[\pi_{h}^{X}\right]=\bar{\pi}+\frac{(1-\delta)^{2}}{4\left(1-\delta^{2}\right)} \sigma_{\alpha}^{2}+\frac{(1-x)^{2}}{4\left(1-\delta^{2}\right)} \sigma_{h, H}^{2}+\frac{(1-x)^{2} \delta^{2}(1-x)^{2}}{\left(4-\delta^{2}\right)^{2}\left(1-\delta^{2}\right)} \sigma_{f, F}^{2}
\end{aligned}
$$

With FDI, using the expression for $p_{j}^{F D I}$ and taking the expectation of (18), yields

$$
E\left[\pi_{j}^{F D I}\right]=\bar{\pi}+\frac{(1-\delta)^{2}}{\left(2-\delta^{2}\right)\left(1-\delta^{2}\right)} \sigma_{\alpha}^{2}+\frac{(1-x)^{2}(1-\delta)^{2}}{\left(2-\delta^{2}\right)\left(1-\delta^{2}\right)} \sigma_{H}^{2}
$$

As the firms are facing the same cost shock with FDI, there is only one variance term for the cost shock, subscripted as before with $\mathrm{H}$. 


\subsection{The access mode choice for the foreign firm}

From (20) and (21), the foreign firm chooses FDI if and only if

$$
\begin{aligned}
E\left[\pi_{f}^{F D I}\right]-E\left[\pi_{f}^{X}\right]=\frac{(2+\delta)^{2}(1-\delta)^{2}}{\left(4-\delta^{2}\right)^{2}(1-\delta)^{2}} \sigma_{\alpha}^{2}+\frac{(1-x)^{2}(2+\delta)^{2}(1-\delta)^{2}}{\left(4-\delta^{2}\right)^{2}(1-\delta)^{2}} \sigma_{H}^{2} & \\
& -\frac{(1-x)^{2}\left(2-\delta^{2}\right)^{2}}{\left(4-\delta^{2}\right)^{2}(1-\delta)^{2}} \sigma_{f, F}^{2}>0
\end{aligned}
$$

Learning the home country demand still is valuable to the foreign firm when it competes in prices as shown by the first term on the RHS of (22). Similarly, the correlating of cost shocks and learning is still harmful (just as it was with quantity competition) to the foreign firm because the second and the third term on the RHS of (22) sum to less than zero under the assumption of equal cost variance across countries. Indeed, comparing (22) with (11) shows that the coefficients are quantitatively very similar (and exactly equal if $\delta=0$ ) to those in quantity competition. As a result, we obtain a similar condition as we did with quantity competition:

Proposition 5 When firms compete in prices, the foreign firm chooses FDI (over export) (A) if the demand uncertainty is sufficiently greater than the cost uncertainty, (B) if the goods are sufficiently differentiated, or $(C)$ if production costs are not too locally dependent. That is, FDI is profitable if and only if

$$
\sigma_{\alpha}^{2} \geq \delta \frac{(1-x)^{2}\left(4-\delta-2 \delta^{2}\right)}{(2+\delta)^{2}(1-\delta)^{2}} \sigma_{c}^{2}
$$

Examination of (23) reveals that the forces behind the foreign firm's choice of FDI in price competition are the same as in quantity competition. The inequality in (23) holds only if demand variance is just slightly larger than is needed in quantity competition. For example, if $\delta=3 / 4$, then the above condition is approximately $\sigma_{\alpha} \geq 1.8(1-x) \sigma_{c}$, while with quantity competition the condition is approximately $\sigma_{\alpha} \geq 1.3(1-x) \sigma_{c}$. Further, for both price and quantity competition, the value from learning demand information decreases as the 
goods become closer substitutes ( $\delta$ increases). ${ }^{16}$ For example, in the case of equal variance and all local content $(x=0)$, the maximum $\delta$ at which FDI is preferred is just slightly lower (approximately one-half) with price competition than with quantity competition.

\subsection{Home country welfare}

We begin with the effect of FDI on the home firm. Using (20) and (21) we have

$$
\begin{aligned}
E\left[\pi_{h}^{F D I}\right]-E\left[\pi_{h}^{X}\right]=\frac{\delta(4-\delta)(1-\delta)^{2}}{4\left(1-\delta^{2}\right)(2-\delta)^{2}} \sigma_{\alpha}^{2}-\frac{\delta(1-x)^{2}(4-3 \delta)}{4\left(1-\delta^{2}\right)(2-\delta)^{2}} \sigma_{H}^{2} & -\frac{\delta^{2}(1-x)^{2}}{4\left(4-\delta^{2}\right)^{2}(2-\delta)^{2}} \sigma_{f, F}^{2} \\
& -
\end{aligned}
$$

Here, price competition has a different qualitative effect on demand learning: the home firm benefits from the foreign firm learning the home demand intercept, whereas it was harmed in quantity competition. This is because in price competition a rival's response to demand information amplifies the demand shock: when there is a high (low) demand intercept, a rival responds with a higher (lower) price, which is equivalent to an even greater (smaller) demand intercept for the firm (see Equation 19). This is akin to a mean-preserving spread in the distribution of the demand intercept. ${ }^{17}$ In contrast, in quantity competition when there is high (low) demand, the rival increases (decreases) output, which is akin to dampening the change in the demand intercept. Despite this difference in demand learning, the home firm can still be harmed by FDI because the demand effect is indirect and small relative to the loss from the correlation effect. As a result, unless the demand uncertainty is much greater than the cost uncertainty or local content is sufficiently small (large $x$ ), the home firm is harmed by FDI that is profitable for the foreign firm. From (23) and (24) we have

Proposition 6 When firms compete in prices, profitable FDI harms the home firm if cost

\footnotetext{
${ }^{16}$ The reason with price competition differs though. With perfect substitutes and constant marginal cost the equilibrium is determined by the marginal cost (so long as marginal cost is less than the demand intercept) and so learning the exact demand intercept has no value. Thus, as the goods become closer substitutes the value of learning the demand intercept decreases (as it does with quantity competition)

${ }^{17}$ This effect also exists for the foreign firm, but it is secondary because the size of the price changes from a change in $\alpha$ decreases faster in $\delta$.
} 
uncertainty is sufficiently large and locally dependent:

$$
\sigma_{\alpha}^{2} \leq \frac{(1-x)^{2}\left(16+8 \delta-8 \delta^{2}-3 \delta^{3}\right)}{(2+\delta)^{2}(1-\delta)^{2}(4-\delta)} \sigma_{c}^{2}
$$

Note that the RHS of (25) is greater than the RHS of (23) - the condition for FDI to be profitable. That is, for given $x$ and $\delta$ there exist a $\sigma_{\alpha}^{2}$ that satisfies (25).

Consider next home consumer welfare. If the foreign firm exports, substituting the equilibrium prices and quantities into (1) and taking the expectation yields

$$
E\left[C S^{X}\right]=\overline{C S}+\frac{(1-\delta)(5+3 \delta)}{8\left(1-\delta^{2}\right)} \sigma_{\alpha}^{2}+\frac{(1-x)^{2}}{8\left(1-\delta^{2}\right)} \sigma_{h, H}^{2}+\frac{(1-x)^{2}\left(4-3 \delta^{2}\right)}{2\left(4-\delta^{2}\right)^{2}\left(1-\delta^{2}\right)} \sigma_{f, F}^{2} .
$$

If the foreign firm chooses FDI, then expected consumer surplus is

$$
E\left[C S^{F D I}\right]=\overline{C S}+\frac{1}{(1+\delta)(2-\delta)^{2}} \sigma_{\alpha}^{2}+\frac{(1-x)^{2}}{(1+\delta)(2-\delta)^{2}} \sigma_{H}^{2} .
$$

The effect of FDI on home consumer surplus is

$$
\begin{array}{r}
E\left[C S^{F D I}\right]-E\left[C S^{X}\right]=-\frac{(1-\delta)^{2}\left(12+4 \delta-3 \delta^{2}\right)}{8\left(1-\delta^{2}\right)(2-\delta)^{2}} \sigma_{\alpha}^{2}+\frac{(1-x)^{2}\left(4-4 \delta-\delta^{2}\right)}{8\left(1-\delta^{2}\right)(2-\delta)^{2}} \sigma_{H}^{2} \\
-\frac{(1-x)^{2}\left(4-3 \delta^{2}\right)}{8\left(1-\delta^{2}\right)(2-\delta)^{2}} \sigma_{f, F}^{2} .
\end{array}
$$

From (26) we find the second difference between price and quantity competition. With price competition consumers do not like the firms learning demand. The reason is that when consumers value the product more, the firm raises its price, and when they value the product less the firm lowers the price (while with quantity competition, when consumers value the product more, the firm produces more so the price decreases). Combined with their harm from the correlation effect, consumers are harmed when the foreign firm chooses FDI. From (26) (recalling that $\sigma_{H}^{2}=\sigma_{i, N}^{2}=\sigma_{c}^{2}$ ) we obtain:

Proposition 7 When the firms compete in prices, profitable FDI reduces expected home consumer surplus. 
Turning to home country welfare from (24) and (26) we have

$$
\begin{aligned}
E\left[W^{F D I}\right]-E\left[W^{X}\right]=-\frac{(1-\delta)^{2}\left(12+8 \delta+\delta^{2}\right)}{8} & \sigma_{\alpha}^{2} \\
& \quad+\frac{\left(1-\delta^{2}\right)\left(4-\delta^{2}\right)}{8\left(1-\delta^{2}\right)\left(4-8 \delta-5 \delta^{2}\right)} \sigma_{H}^{2}-\frac{4(1-x)^{2}}{8\left(1-\delta^{2}\right)\left(4-\delta^{2}\right)} \sigma_{f, F}^{2} .
\end{aligned}
$$

From (26) we know that consumers are harmed by profitable FDI. The home firm could benefit from profitable FDI, only if demand uncertainty is far greater than cost uncertainty. However, in that case consumers are harmed even more. The net result, as is clear from (27), is that the home country is made worse off.

Proposition 8 Profitable FDI reduces expected home country welfare.

Recall from Proposition 4 that in quantity competition FDI usually reduces home country welfare except when goods are sufficiently differentiated and at the same time either demand uncertainty is sufficiently greater than cost uncertainty, or production cost is not too locally dependent. As Proposition 8 shows, in price competition these exceptions do not exist. The only key is that consumers benefit from FDI in quantity but not in price competition. However, that effect is secondary, so the overall welfare effect is qualitatively the same: profitable FDI harms home welfare.

\section{Conclusion}

We consider information-based FDI decisions under uncertainty when a foreign firm competes strategically with a home firm in the home market. Our analysis has two features that make it distinct from other works investigating similar issues. First, while other works study the effect of either demand uncertainty or cost uncertainty in isolation, we examine them both and show that their interplay is essential in the access mode selection between FDI and exporting. Second, FDI generates a hitherto unexamined effect, which we call correlated learning. Namely, FDI allows the foreign firm to learn home demand and cost, which by itself would increase its expected profit. However, FDI also means buying labor and other 
inputs from the same national market as does the home firm, which correlates the firms' costs and changes the nature of learning from being about a private cost parameter to one about a common cost parameter. This correlated learning effect reduces the value from learning cost information and can make FDI unprofitable. FDI decision hinges on the balance of the benefit from learning demand shocks against the harm from the correlation effect on learning. A key insight is that if cost uncertainty is too great or there is too much "local content" so as to correlate costs more, then the foreign firm does not choose FDI even though it gains information. This suggest (but not modeled here) that FDI may beget more FDI; that is, as FDI globalizes the input market to reduce the significance of local cost shocks, it may encourage other firms in the future to opt for FDI over exporting in the output markets. Another implication of our finding is that, when choosing FDI, firms may act to reduce the learning correlation, for example by choosing a production location different from their rivals, or hiring non-unionized workers when the home firm has unionized workers as has been done with Japanese automakers in the US.

Our second finding is that the FDI decision also depends on the substitutability between the goods the firms produce. Somewhat counter-intuitively, the more homogeneous the goods, the less valuable the demand information acquisition is to the foreign firm in both price and quantity competition, though for different reasons. In quantity competition, that is because a firm's ability to exploit the information is mitigated by the rival's reaction to this same information. In price competition the rival's response does benefit the firm. ${ }^{18}$ Yet, as the goods become closer substitutes, information about the demand intercept becomes less important for the equilibrium prices; indeed, with Bertrand competition (i.e., perfect substitutes) the equilibrium price is determined only by cost. The upshot is our second insight: the more substitutable the goods, the less valuable the demand information is and hence the more likely that the foreign firm chooses exporting over FDI in both price and quantity competition.

Turning to home welfare analysis, we find that profitable FDI is likely to decrease home

\footnotetext{
${ }^{18}$ For example, when the firm learns that demand is stronger than expected, it raises its price and the rival raises its price to the firm's benefit.
} 
country welfare. The exception to this conclusion occurs if firms compete in quantities and if these two additional conditions are satisfied: (i) the goods are sufficiently differentiated; and (ii) demand uncertainty is sufficiently greater than cost uncertainty or there is sufficiently little local content. These two conditions two reduce the harm from the correlation effect while quantity competition means that home consumers benefit. Our analysis gives a rationale for the host country's desire to regulate incoming FDI. It suggests in particular that the host country is keener in regulating FDI if it has a local competitor that produces a close substitute to the foreign firms product, there is strong demand uncertainty, and there is a large use of local inputs. It also suggests that policy requiring "local" input content is likely to be at odds with a policy encouraging FDI, as local content reduces the attractiveness of FDI even if the local input is cheaper in expectation. More importantly, local content requirements can turn what would have been home welfare improving FDI without the government distortions into welfare reducing FDI with the distortions.

Our results shed light on other work examining similar issues. For example, consider the Qiu and Zhou (2006) analysis of international merger mentioned earlier; while merger is unprofitable in Cournot oligopoly, there is a case for international merger when demand is uncertain, because the foreign firm, learning home market demand through merger, may be able to compensate the partner for the loss of profit from the merger (Salant, et al. 1983) and from the information loss. There is however an unasked question here: if the foreign firm can choose FDI instead of merger, it can capture the information rent without compensating the home partner for the loss of profit. Thus, in the Qiu and Zhou (2006) environment greenfield FDI may dominate merger. While sufficiently high set-up cost may provide one reason the foreign firm chooses merger instead of FDI, our model provides another: if cost uncertainty is also present in their environment FDI may be less profitable than merger, and also gives the foreign firm a better threat point when negotiating with a home rival over a merger.

Our analysis suggests several directions in future research. One would be to consider other types of learning. For example, propinquity of production allows firms to gain specific information regarding the rivals, including firm-specific demand information (as opposed to 
common demand examined here) and firm-specific cost information. A second possibility is to relax our assumption regarding equal cost variances, which would change the relative value of learning the country specific costs. The implication though is relatively straightforward, e.g., greater home cost uncertainty would make FDI relatively more attractive. A third way in which to extend the results would be to have more than one foreign or home firm as this can affect the welfare implications. These possible extensions are left for future research. 


\section{References}

[1] Aizenman, J. and N. Marion, 2004, The merits of horizontal versus vertical FDI in the presence of uncertainty, Journal of International Economics, 62, 125-48.

[2] Bagwell, Kyle and Robert Staiger, 2003, Informational aspects of foreign direct investment," Japan and the World Economy, 2003, 15(1), 1-20.

[3] Caves, R. E., 1971, International corporations: the industrial economics of direct investment, Economica 38, 1 - 27.

[4] Caves, R. E., 1996, Multinational enterprise and economic analysis, 2nd edition, London: Cambridge University Press.

[5] Creane, A., 2007, Productivity Information in Vertical Sharing Agreements, International Journal of Industrial Organization, Vol. 25(4), 821-841.

[6] Creane, A. and K. Miyagiwa, 2007, Export, Foreign Direct Investment, and Joint Ventures: Learning the Rival's Costs through Propinquity, ISER Discussion Paper 0691, Institute of Social and Economic Research, Osaka University.

[7] Creane, A., and K. Miyagiwa, 2008, Information and Disclosure in Strategic Trade Policy, Journal of International Economics, Vol. 75(1), 229-244.

[8] Ethier, W. J., 1986, The multinational firm, Quarterly Journal of Economics 101 (November), $805-833$

[9] Etro, F., 2011, Endogenous market structures and strategic trade policy, International Economic Review, 52: 63-84

[10] Gal-Or, E. 1986, Information transmission - Cournot and Bertrand equilibrium, Review of Economic Studies 53, 85-92

[11] Helpman, E., 1984, A simple theory of trade with multinational corporations, Journal of Political Economy 92, 451-471. 
[12] Horstmann, I. J., and Markusen, J. R., 1996, Exploring new markets: direct investments, contractual relations and the multinational enterprise, International Economic Review $37,1-19$.

[13] Katayama, S., and K. Miyagiwa, 2009, FDI as a signal of quality, Economics Letters 103, 127-130.

[14] Markusen, J. R.; 1984, Multinational enterprises, multi-plant economies, and the gains from trade, Journal of International Economics 16, 205-226.

[15] Markusen, J. R.; 1995, The boundaries of multinational enterprises and the theory of international trade. Journal of Economic Perspectives, Vol. 9, No. 2, Spring, 169-189.

[16] Markusen, J. R., 2002, Multinational firms and the theory of international trade; Cambridge, MIT Press.

[17] Qiu, L. D., 1994, Optimal strategic trade policy under asymmetric information, Journal of International Economics 36, 333-354.

[18] Qiu L. D. and W. Zhou, 2006, International mergers: incentives and welfare, Journal of International Economics 68, 38-58.

[19] Rob, R. and N. Vettas, 2003, Foreign direct investment and exports with growing demand, Review of Economic Studies 70, 629-648.

[20] Salant, Stephen W., Sheldon Switzer, and Robert J. Reynolds, 1983, Losses from horizontal merger: the effects of an exogenous change in industry structure on Cournot-Nash equilibrium, The Quarterly Journal of Economics, vol. 98(2), pages 185-99.

[21] Schlee, E., 2008, Expected consumer's surplus as an approximate welfare measure, Economic Theory, 34, 127-155.

[22] Sung, H., and H. E. Lapan, 2000, Strategic foreign direct investment and exchange-rate uncertainty, International Economic Review 41, 411-423. 
[23] Vives, X. 1984, Duopoly information equilibrium: Cournot and Bertrand, Journal of Economic Theory 34, 71-94.

[24] Vives, X., 1990, Trade association disclosure rules, incentives to disclose information and welfare. Rand Journal of Economics 21(3): 409-30. 